Second, most articles appear to have been completed in 1965 , about two years before publication. This is not a disadvantage as long as the contributions are recognized as digests of the relevant literature up to 1964/65. The price of the book is high, but it is well produced and the illustrations appear good.

The first and second volumes of this treatise constitute a most useful contribution to the study of development. They will be valuable as reference books for several years to come, especially for graduate students and research workers. It is perhaps unfortunate that two other books composed of collections of essays on the biochemistry of development should also have been published very recently: Current Topics in Developmental Biology, Vol. 1, and Comprehensive Biochemistry, Vol. 28, edited by Florkin and Stotz. The latter together include review articles by no less than five of the same authors as have contributed to The Biochemistry of Animal Development. In at least one case the two contributions of the same author are not easily distinguishable.

J. B. GURDON

\section{EXCITABLE CELLS}

\section{The Molecular Properties and Evolution of Excitable Cells}

Vol. 35. By C. J. Duncan. (International Series of Monographs in Pure and Applied Biology: Division of Zoology.) Pp. xi +233 . (Oxford, London and New York: Pergamon Press, Ltd., 1967.) 70s. net.

THE object of this monograph is to present a concrete hypothesis linking the evolution and the molecular properties of excitable cells. This is a formidable task, made all the more so by the multi-disciplinary approach entailed in any attempt to formulate a comprehensive theory. The author takes as his starting point the findings in two neurophysiological monographs published in 1964 on axonal and synaptic transmission by the two distinguished authorities, namely A. L. Hodgkin and Sir Jack Eccles. In the presentation of his theory concerning the phenomena underlying these findings, he adduces supporting evidence which is largely that available in the relevant reviews in histochemistry, electronmicroscopy, biochemistry, molecular biology, pharmacology and physiology.

Obviously, such a theory can only represent the views of one man, Dr. Duncan, and attempts to collate findings in many fields call for critical selection and the discarding of data from the plethora of those available. Selection of data, together with the interpretations placed thereon, carries the personal imprint of Dr. Duncan and, of course, can hardly be expected to receive universal approbation but, nevertheless, this brave attempt can hardly fail to stimulate its readers.

Dr Duncan points out that the primitive form, amoeba, reacts to mechanical deformation of its surface membrane by a locomotor action combining receptor and effector in one cell. Development interpolates a conducting cell or neurone which provides a specialized mechanism for excitation by stimuli, propagation of the excitation and its delivery to an effector cell. This development of rapid transmission of excitation by the axon requires little modification of inherent membrane properties.

In this volume Dr Duncan discusses the mechanoreceptors and the evidence for an enzyme transducer mechanism in sensory cells and attempts to relate ATPases with cation-permeability. He turns then to the mechanisms by which ehemical, thermal and light stimuli are converted into nerve impulses. Dr Duncan shows that transduction of these four forms of stimuli could arise from a common underlying mechanism, a further example of supreme exploitation by Nature on the lines of the utmost economy. He goes on to consider cholinergic synapses and the relation of acetylcholine and cholinesterases to substances which modify synaptic function. The roles of adrenaline, noradrenaline, $\gamma$-aminobutyric acid (GABA) and of inhibitory synapses are considered and then sodium permeability and the release of synaptic chemical transmitters are examined. He touches on RNA and Nissl substance and on the fascinat. ing hypothesis of the incorporation of a memory trace within the RNA molecule.

In the final chapter, Dr Duncan summarizes the main points of his theory and provides a master diagram to illustrate the main components and the points at which it is vulnerable to chemical agents. He relies strongly on pharmacological findings but some may feel that his speculations based thereon ask, in some instances, more from the evidence than is justified.

While the book would be unsuitable for medical, dental and ophthalmic optical students, it could prove of special value to senior B.Sc. students and graduates in the biological sciences because of its trans-disciplinary approach and wealth of information together with references to review sources which might not otherwise come to the attention of its readers.

It should be read, however, as a scholarly attempt to correlate knowledge from many different sources and to provide intellectual stimulation to critical assessment of the evidence and of the author's speculations. Such books are invaluable as catalysts of new ideas and new research and should be found a place in every biological library.

J. P. Quilliam

\section{YEASTS ALIVE}

The Life of Yeasts

Their Nature, Activity, Ecology, and Relation to Mankind. By H. J. Phaff, M. W. Miller and E. M. Mrak. (Harvard Books in Biology, No. 5.) Pp. ix + 186. (Cambridge, Mass.: Harvard University Press; London: Oxford University Press, 1966.) 44s. net.

THIs small volume makes no pretence to being comprehensive. Thus it is practically devoid of chemical formulae and makes little more than passing reference to well-known uses of yeasts on the large-scale such as in baking, brewing and wine-making. This latter remark is, however, in no way an adverse comment. It is rather intended to show how welcome is this simple but wide-ranging account of a field which for various reasons has hitherto mostly been described only in a few specialized texts or in many respects only piecemeal in original publications.

For instance, "yeast life" here basically embraces yeast morphology and life cycles. Topies such as yeast cytology, genetics, nutrition and ecology comprise ancillary fields while yeast spoilage and industrial uses of yeasts are treated more in an illustrative than in a fully descriptive way. The result is an essay which is not only interesting but well balanced and scholarly. Most botanists and microbiologists will appreciate this book as a more coherent account within its limitations of space than has hitherto been available. The individual specialist in, for example, yeast genetics or biochemical transformations will of course be aware of important developments which the authors have not included but will be agreeably surprised by the succinct way in which so much has been co-ordinated. Most readers including specialists will be surprised to learn or be reminded how recent are many of the findings in this field. It is easy to forget that the very concept of yeasts as distinct from other unicellular organisms is only about a century old, that the early faltering attempts at classification go back only about seventy years, that the first really systematic scheme of Stelling-Decker dates from 1931 and that even the present taxonomic sch.cmes of Lodder.Kreger van Rij (1952) and Kudriavzev (1954) together with technical methods (for 